\title{
El maestro Luis Enrique Galván y el indi- genismo en Ayacucho-Perú, siglo XX
}

\author{
RANULFO CAVERO CARRASCO \\ Universidad Nacional de San Cristóbal de Huamanga - Perú \\ Recibido el 28-12-2017; primera evaluación el 10-12-2018; \\ segunda evaluación el 28-12-2018; aceptado el 29-12-2018
}

\section{Resumen}

El objetivo de la investigación es analizar y comprender el pensamiento del destacado maestro ayacuchano (Perú) Luis E. Galván Candiotti sobre la educación en general y sobre la educación indígena en particular, en las primeras seis décadas del siglo XX. Para ello, distinguimos dos etapas en su pensamiento y accionar: desde 1925 hasta cuando ejerció el cargo de director de Educación Indígena del Ministerio de Instrucción Pública (1931-1932), cuya producción fue superior (sobre todo referida a la educación indígena) y, luego de este periodo, hasta cuando fallece en 1966. Pertenece a la generación temprana de intelectuales indigenistas ayacuchanos, y dentro del contexto nacional, su pensamiento se difunde durante la ejecución de dos proyectos nacionales de educación: el civilista hasta 1940 y el indigenista a partir de 1941. Nuestro sustento teórico gira básicamente en torno a Pierre Bourdieu sobre el "campo intelectual» (2002), a Carlos Altamirano «sobre los intelectuales» (2013) y a Gerardo Perafán respecto al «pensamiento del profesor» (2005). Para el análisis e interpretación del pensamiento del maestro Galván, construimos categorías o dimensiones en base a las fuentes revisadas: básicamente bibliográficas, hemerográficas y documentales, que fueron evaluadas y sometidas a la crítica histórica. El maestro indigenista asumió plenamente el influjo de la Escuela Nueva y relacionó el "problema indígena» al "problema nacional», siendo en el Perú uno de los prolegómenos tempranos más importantes del tránsito de la «educación para indios» a la educación bilingüe y, de esta, a la educación intercultural.

Palabras clave: Luis E. Galván, educación, indigenismo, campo intelectual.

\footnotetext{
* Doctor en Ciencias Sociales por la Universidad Estadual de Campinas (Brasil), con Diploma de Segunda Especialidad en Políticas Educativas y Desarrollo Regional (PUCP). Ha publicado libros y artículos científicos sobre temas de educación, antropología y conflicto armado interno. Ha sustentado sus ponencias en versiones del Congreso Iberoamericano de Historia de la Educación Latinoamericana. Fue decano de la Facultad de Ciencias de la Educación de la Universidad Nacional de San Cristóbal de Huamanga; actual docente de pre y posgrado en esa Facultad. Correo: cavero.j@pucp.pe
} 


\section{The teacher Luis E. Galván and the indigenism in Ayacucho-Perú, 20th century}

\section{AbSTRaCT}

The aim of this research is to analyze and to understand the thoughts of the excellent teacher Luis E. Galván Candiotti from Ayacucho (Peru) about education and especially on the indigenous education, in the first six decades of the 20th century. For this, we had to distinguish two stages in his thought and behavior: from 1925 until he was the Director of Indigenous Education of the Department of Public Instruction (1931-1932), whose production was more ideal (especially recounted to the indigenous education) and after this period till when he expired in 1966. The teacher Galván belongs to the early generation of intellectual indigenists from Ayacucho, and inside the national context, his thought is given during the execution of two national educational projects: the "civilista" until 1940 and the «indigenista» from 1941. Our theoretical basis is founded basically in Pierre Bourdieu thoughts about «intellectual field» (2002), to Carlos Altamirano «on the intellectuais» (2013) and Gerardo Perafán on «teacher thinking» (2005). For the analysis and interpretation of Galván thoughts, we constructed categories or dimensions on the basis of the checked sources: basically bibliographical resources, journalistic material and documentary evidence. They were evaluated and submitted to the historical criticism. The indigenist teacher assumed fully the influence of the New School and related the «indigenous problem» to the «national problem». Peru was one of the most important early prefaces from the «education for Indians» to the bilingual education and then to the intercultural education.

Keywords: Luis E. Galván, education, indigenism, intellectual field.

\section{O professor Luis Enrique Galván y o indigenismo em Ayacucho-Peru, séculoXX} RESUMO

O objetivo da pesquisa é analisar e compreender o pensamento de mestre proeminente ayacuchano (Peru) Luis E. Galván Candiotti na educação em geral e educação indígenas, em particular, nas seis primeiras décadas do século XX. Para fazer isso, podemos distinguir duas fases em seu pensamento e ações: de 1925 até eles ocupou o cargo de diretor de educação indígena do Ministério da Instrução Pública (1931-1932), cuja produção foi otimizada (especialmente em relação à educação indígena) e após este período, até que morreu em 1966. Mestre Galván pertence a geração precoce de intelectuais indigenistas ayacuchanos, e no contexto nacional o seu pensamento é dado durante a execução de dois projetos de educação nacional: o civilisme até 1940 e o movimento indígena a partir de 1941. Nosso suporte teórico basicamente gira em torno de Pierre Bourdieu no «campo intelectual» (2002), de Carlos Altamirano «sobre os intelectuais» (2013) e Gerardo Perafán "sobre o pensamento do professor» (2005). Para a análise e interpretação do pensamento do mestre Galván, construir categorias ou dimensóes com base nas fontes revisadas: principalmente bibliográficas, periódicos e documentários, que 
foram avaliados e submetidos à crítica histórica. $\mathrm{O}$ mestre indiano, totalmente ao influxo da escola nova relacionó o "problema indígena» ao "problema nacional», sendo em o Peru um dos mais importantes que fez o mudança de 'educaçáo para os índios' a la educação bilíngue e de até a la educacao intercultural.

Palavras-chave: Luis E. Galvan, ensino, indigenismo, campo intelectual.

\section{INTRODUCCIÓN}

El centralismo académico limeño y la pugna al interior del campo intelectual han invisibilizado a grandes educadores del interior del país. Es el caso de Luis Enrique Galván Candiotti, del que no existe un solo trabajo sistematizado como el que presentamos ahora. Consideramos que es el maestro indigenista más destacado de Ayacucho. Su pensamiento y acción rebasan el ámbito regional y su importancia se encuentra al nivel de otros prominentes maestros indigenistas peruanos.

Nació en Ayacucho, capital del departamento del mismo nombre, ubicado en la sierra centro-sur del Perú, el 7 de marzo de 1892 y murió en Lima el 23 de setiembre de $1966^{1}$. Su formación como docente la realizó en la antigua y prestigiosa Escuela Normal de Varones de Lima, de la que egresó en $1909^{2}$. También se graduó como abogado en el ańo 1919 en la ciudad de Lima.

En el campo educativo ocupó diversos cargos y trabajó en varios lugares: en 1924 fue director del antiguo y emblemático Colegio Nacional de San Ramón de Ayacucho³; en 1929 trabajó en el Instituto Pedagógico de Varones de Lima y, en 1937, en la Universidad Nacional Mayor de San Marcos. Fue secretario general del Ministerio de Instrucción Pública; y, de 1931 a 1932, ocupó el cargo de director de Educación Indígena del Ministerio del ramo,

\footnotetext{
1 Su padre Rafael (a los 24 años de edad), fue profesor en 1855 en el naciente Colegio Nacional de San Ramón de Ayacucho, de las asignaturas de Filosofía, Religión y Aritmética; posteriormente se desempeńó como presidente del Consejo Departamental de Instrucción Pública y senador de la República.

2 La emblemática Escuela Normal de Varones de Lima fue fundada en 1905, encargando su dirección al educador belga Isidoro Poiry, a quien se debe la introducción en el Perú de la Escuela Nueva que fue difundida por todo el país por los normalistas egresados de esta Escuela (Chileno, s/f). La primera promoción egresó en 1907, y uno de sus integrantes, Manuel Antonio Hierro Pozo, fue otro distinguido maestro ayacuchano (Cavero, 2015).

3 También habría sido el «antiguo rector» o director del Colegio Nacional Mariscal Cáceres de Ayacucho. ¿Es el antiguo Colegio San Ramón antecesor del Mariscal Cáceres o es el mismo Colegio Nacional Mariscal Cáceres? Aspecto que aún sigue sin esclarecer.
} 
uno de los cargos más altos y controvertidos asumidos por un maestro ayacuchano ${ }^{4}$. En 1948 fue director regional de Educación del Centro del Perú.

Fue delegado en 1930 al IV Congreso Panamericano del Niño realizado en Lima. Formó parte del prestigioso Centro Cultural Ayacucho, sobre todo en su primer momento, que va desde su fundación hasta la reapertura de la Universidad de Huamanga en 1959 y destacó como articulista en temas educativos al lado de Manuel Antonio Hierro Pozo, Augusto Madueño, Lucio Alvizuri, Luis Milón Bendezú, Gustavo Castro Pantoja y otros importantes maestros ayacuchanos. El Centro Cultural Ayacucho fue la institución cultural más importante de la región, aún no superada hasta ahora por una similar, solo reemplazada, en parte, por el papel que cumplió la Universidad Nacional de San Cristóbal de Huamanga después de su reapertura en 1959. Fue fundado el 12 de octubre de 1934, a iniciativa del doctor Alfredo Parra Carreño. Durante su larga existencia, hasta 1965, publicó cien números de su revista Huamanga.

A diferencia de otros maestros indigenistas coetáneos, como José Antonio Encinas y José María Arguedas, el maestro Galván, al parecer, no salió al extranjero. En 1941, como presidente de la Asociación Nacional de Escritores, Artistas e Intelectuales del Perú, mantuvo una posición contestataria contra el capitalismo extranjero que operaba en las minas de Cerro de Pasco y La Oroya. En 1945-1948, fue senador de la República en representación de Ayacucho y se interesó por la educación de niños y jóvenes de su tierra. En su segundo periodo como senador de la República (1950-1956), y estando como presidente de la Comisión de Educación del Congreso, el maestro puneño José Antonio Encinas presentó el proyecto de ley para la reapertura de la Universidad de Huamanga que fue clausurada después de la guerra con Chile por problemas presupuestales, la que fue lograda más tarde.

Además de las mencionadas en las referencias bibliografícas del presente trabajo, tuvo muchas otras publicaciones 5 . José Carlos Mariátegui (1968), en sus 7 Ensayos de Interpretación de la Realidad Peruana, hace un breve comentario a su artículo sobre la investigación científica en las universidades del Perú,

\footnotetext{
4 Otro maestro ayacuchano, el doctor Alfredo Parra Carreño, en la década de 1960, llegó a ser ministro de Educación durante un corto tiempo.

5 Entre ellas: Estudio paidológico del niño peruano (1927); ¿Qué hace nuestra Universidad por la investigación científica? (1927); Ayacucho y sus necesidades; El colegio San Ramón y su centenario; San Martín, Bolivar y Simón Rodríguez propulsores de la educación en el Perú; Homenaje al maestro peruano; Filosofía y antropología educativa; Psicología y sociología educativa. En 1958 escribió Reflexiones sobre una pedagogía universitaria, aplicable al Perú, etc. Una de sus obras fue prologada por el ministro de Instrucción y recibió elogios de un profesor de psicología de la Sorbona y otra fue una edición oficial en español e inglés a cargo de la Unión Panamericana de Washington.
} 
publicado en la famosa revista Amauta $\mathrm{N}^{\circ} 7$ (1929) que dirigía Mariátegui. Al respecto, dice: «hace poco, un alto funcionario de Educación Pública, el doctor Luis E. Galván, se preguntaba en un artículo: ¿qué hace nuestra Universidad por la investigación científica? A pesar de sus sentimientos de adhesión a San Marcos, el doctor Galván se veía precisado a darse una respuesta totalmente desfavorable» $(1968 \text {, p. 117, 118 })^{6}$.

Luis E. Galván obtuvo varios reconocimientos y distinciones. En 1959 recibió Palmas Magisteriales de Primera Clase (el honor más alto otorgado en el Perú a los maestros extraordinarios); en 1966, la reabierta Universidad Nacional de San Cristóbal de Huamanga le rindió un merecido homenaje colocando una placa en un aula del edificio Garcilaso de la Vega; y el Ministerio de Educación designó con su nombre al colegio nacional mixto del distrito de Laramate, provincia sureña de Lucanas (Ayacucho).

\section{Contexto en el Que trabajó Galván}

Estamos ante un destacado maestro ayacuchano de la generación temprana de intelectuales indigenistas del siglo XX, al lado de otros similares de Ayacucho y del Perú. En general, Galván trabajó en un contexto regional caracterizado, según el Censo Nacional de 1940, por la existencia de una considerable población indígena, un alto porcentaje de población monolingüe quechua, escasa cobertura escolar y alto porcentaje de analfabetismo ${ }^{7}$; asimismo, por el desarrollo de corrientes indigenistas ${ }^{8}$. Otra característica fue la labor que venía desplegando una pléyade de extraordinarios maestros particularmente de las ciudades de Ayacucho y Huanta. Circulaba una variedad de revistas educativas editadas por colegios y escuelas. Varios intelectuales, entre ellos maestros (agrupados en el Centro Cultural Ayacucho), generaban permanentes deba-

\footnotetext{
6 Galván colaboraba con artículos en la revista Amauta. Conocemos de otro que escribió en el № 24 (junio, 1929) titulado "La orientación educacional de los jóvenes». Si bien no encontramos en las publicaciones del maestro ayacuchano alguna alusión expresa al pensamiento de Mariátegui, tampoco señaló abiertamente su adhesión al marxismo, notamos algunas coincidencias con el autor de 7 Ensayos sobre la educación indígena y su relación con los aspectos económicos, sociales y políticos.

7 En Ayacucho, según el Censo Nacional de 1940, la población quechuahablante monolingüe mayor de 5 años representaba el 82,37\%. El porcentaje de niños de 6 a 14 ańos con instrucción llegaba solo al 15,7\%. El analfabetismo llegaba a 85,31\% de la población de 15 a 100 ańos (Cavero y Cavero, 2007).

8 Entre los ańos de 1920 a 1950 una de las reivindicaciones más sentidas en la ciudad de Ayacucho es el indigenismo. En 1930 sale a luz el Semanario indigenista El Pocra y en 1933 la revista Antara. En 1939 se publican dos importantes libros de autores ayacuchanos que influyen en el pensamiento regional: La evolución mítica en el imperio incaico del Tahuantinsuyo, de Recaredo Pérez Palma, y Las tribus de Ancku Wallock, de Víctor Navarro del Águila. En 1940 se edita Nuestro Ayacucho bajo el título de «Peruanizar al indio y no indigenizar al Perú» (Cavero y Cavero, 2007).
} 
tes, especialmente desde la década del 30 sobre la identidad del ayacuchano y sobre la educación indígena (en 1930 funcionaba en Soccoscocha-Huanta la primera escuela rural indígena del país, a cargo del maestro ayacuchano Manuel Antonio Hierro Pozo, y, en 1948, dos maestros ayacuchanos presentan ponencias al II Congreso Indigenista Interamericano del Cusco. Este Congreso fue organizado por el Instituto Indigenista Interamericano con sede en México, evento que como sus similares tuvo una sección de Educación. Luis E. Galván es invitado expresamente a este trascendental congreso y se le solicita una ponencia, desconocemos si presentó o no?.

En el contexto nacional, Galván vivió y trabajó estando vigente sucesivamente dos grandes proyectos educativos nacionales: el civilista hasta (de 1899 a 1940) y el indigenista (de 1941 a 1970). El proyecto civilista, desarrollado fundamentalmente en las dos primeras décadas del siglo XX, tenía como propuesta la «civilización» del indígena, para lo que había que castellanizarlo y dotarle de hábitos occidentales en su salud, nutrición, relaciones sociales y economía. El proyecto indigenista reconocía virtudes en la cultura indígena que debían ser preservadas (el colectivismo agrario y una suerte de espíritu democrático «natural»), y postulaba la conveniencia de alfabetizar a los indígenas en el propio idioma autóctono y de adaptar las estrategias educativas a las características y necesidades de la población rural (Cavero, 2014).

En la ejecución del primer proyecto, desde el Estado se pone en vigencia a partir de 1930 el reglamento orgánico de instrucción, que crea direcciones como las de Educación Indígena y Educación Artística, reforma que algunos calificaron como de «indigenismo educacional». También hubo otras iniciativas desde el Estado dentro de la concepción de «educación para indios» buscando la «homogenización forzada» de la que habla Sinesio López (2009). En el segundo proyecto habrá más aperturas impulsando la educación indígena pero esta vez dentro de la concepción llamada «homogenización amable» (López, 2009) y la «educación bilingüe», sobre todo bajo la influencia de José Antonio Encinas, Luis E. Valcárcel, José María Arguedas y otros. Es decir, para Sinesio López, en ambos proyectos educativos nacionales se buscaría la asimilación del indígena para hacer un país homogéneo, solo cambiaría la forma y los mecanismos para lograrla: en el primer caso en forma forzada a través de su castellanización; en el segundo, en forma amable, valorando y respetando su idioma y su propia cultura.

\footnotetext{
9 Ocupó la presidencia del Congreso José Antonio Encinas (Puno, 1886-1958), en mérito a su dote de educador e indigenista, estando como senador de la República por el departamento de Puno (Portugal, en Encinas, 2007). Por resolución suprema Luis E. Galván es nominado integrante de la delegación peruana a este evento, en su condición de exdirector de Educación Indígena: desconocemos si asistió o no.
} 
Veamos el pensamiento y las propuestas del maestro Luis E. Galván sobre la educación en general y sobre la educación indígena en particular, diferenciando periodos en las que fueron expuestas y realizando algunas comparaciones con otros maestros indigenistas de la época, tanto ayacuchanos como peruanos y con las que se dieron en México. Después, a manera de conclusiones, hacemos una apreciación más general de su obra dentro del campo intelectual ayacuchano y del indigenismo de la época.

\section{Pensamiento sobre la educación en general}

Para tratar el pensamiento del maestro-intelectual Luis E. Galván sobre la educación en el Perú, construimos cinco categorías o dimensiones: a. influencias teóricas y/o de autores; b. concepto de educación; c. fines de la educación; d. sujetos de la educación y e. medios educativos.

En la década de 1920, el maestro Galván tuvo una fuerte influencia de la pedagogía del educador belga Ovide Decroly. Inclusive con una introducción y observaciones aplicables al Perú escritas por él, se publicó un trabajo, así como de Gerard Boon ${ }^{10}$. Junto con otros educadores, Galván tradujo en Lima y adaptó a la realidad peruana los test mentales para su aplicación a los niños, nació de esta manera la psicopedagogía. Más tarde en 1941 se fundó el Instituto Psicopedagógico Nacional (Chileno, s/f).

Sus conceptos sobre la educación y sobre las escuelas los expresa desde la década de 1920 y lo sigue haciendo hasta la década de 1950, como veremos en seguida. En la década de 1920, señala con una visión nacional que la educación en el Perú, después de la primera Guerra Mundial, requiere de reformas y de una transformación radical, máxime cuando es muy débil su misión redentora que socialmente deben llenar las escuelas. Sobre el Perú, Galván (1925) proporciona los siguientes alarmantes datos: para 1925, había un analfabetismo del $65 \%$ de la población, solo el $35 \%$ de la población escolar estaba matriculada y en la calificación mundial de cultura llegaba a muy baja.

Concede gran importancia al factor psicológico y propone la necesidad de elaborar un nuevo programa de trabajo escolar en armonía con los «centros de interés del educando», siguiendo las tres grandes funciones psicológicas del pedagogo Ovide Decroly: observación, asociación y expresión ${ }^{11}$.

\footnotetext{
10 El libro titula Hacia la escuela renovada (1925), publicado bajo los auspicios del Ministerio de Instrucción encabezado por el doctor Alejandro Maguiña.

11 Decroly es un pedagogo del siglo XX, de la llamada corriente pragmatista, específicamente de la escuela de los métodos activos al lado de Montessori. Señala que los niños tienden a percibir los hechos y las cosas como un todo (globalmente). Sugiere que la iniciación a la lectura debe hacerse a través
} 
En la década de 1930, basándose en Platón y Dewey ${ }^{12}$, Galván (1932a) sostiene que en todos los tiempos la educación es el proceso de perfeccionamiento humano: «En su esencia la educación es un proceso de civilización de la humanidad» (p. 1) que se teje con los valores culturales humanos, con los altos ideales de la especie. Para esta segunda idea, se basa en Nietzche, después hace referencias a Max Scheeler, Oswaldo Spencer, Gandhi y Lenin.

En la siguiente década, continúa concediendo importancia al factor psicológico en la educación, al decir: «todos los pedagogos — señalados— proclaman en que la educación debe respetar las características de la psicología humana en la infancia, en la pubertad, en la adolescencia» (Galván, 1948, p. 4).

Más tarde, pensó en la reapertura de la Universidad de Huamanga como una fuerza poderosa para la recuperación socioeconómica y cultural de la vieja Huamanga (nombre antiguo de la ciudad y de la región de Ayacucho), coincidiendo en este punto con otro maestro ayacuchano de la generación intermedia de intelectuales, Moisés Cavero Cazo. En el Plan de Estudios del nuevo Instituto de Educación de esta Universidad, encontramos su influencia; propuso la creación del Instituto de Lingüística. En 1959, al tratar sobre el «Presente y porvenir de Ayacucho» advierte que la región necesita el desarrollo de sus instituciones educativas y culturales «adecuando los tipos de las escuelas a la característica ruralista y de economía subdesarrollada» que tiene (Galván, 1959a, pp. 34-35). De esta forma, en su visión, está la educación como un factor de desarrollo de los pueblos ${ }^{13}$.

Refiriéndose a los fines de la educación, siempre con una visión nacional que lo distingue, critica que las actuales escuelas en el Perú «no preparan al sujeto para la lucha por la vida» y para que ejerzan las «diversas actividades sociales» (1925, pp. 41-42), punto de vista con el que más tarde coincide otro destacado maestro ayacuchano, Augusto Madueño. Aproximadamente,

de frases enteras. El mismo procedimiento recomienda para la programación montada en torno a los centros de interés que busca el aprendizaje globalizador (De Arruda, 1996).

12 John Dewey (1859-1952), influenciado por el pragmatismo de William James, prefiere usar las expresiones instrumentalismo o funcionalismo para identificar su teoría. Es uno de los mayores pedagogos estadounidenses que contribuyó decididamente en la divulgación de los principios de la Escuela Nueva. Hizo severas críticas a la educación tradicional (a la predominancia del intelectualismo y la memorización). Concluye que la escuela no puede ser una preparación para la vida, sino es la propia vida, por eso vida-experiencia-aprendizaje no se separan. La educación tendría la función democratizadora de igualar las oportunidades, que más tarde será criticada por los teóricos crítico-reproductivistas (De Arruda, 1996).

13 En la época en que trabajan Galván y Encinas, además del indigenismo hay otro movimiento intelectual en boga: el positivismo que «atribuye a la educación el papel de motor del desarrollo y progreso económico de la sociedad, planteamientos que fueron recogidos por la llamada Escuela Nueva o Activa» (Marrou, 2003, p. 13). 
por esta misma fecha, también en México, José Vasconcelos, al impulsar el proyecto educativo de la revolución mexicana (y le dio un sentido humanista, nacionalista y culturizante), señaló que la educación consistía en «modelar a los hombres para una función social», es decir prepararlos para desarrollar una función dentro de la sociedad (Lazarín, s/f, p. 11).

Galván menciona, además, que filosóficamente la educación descansa sobre un binomio: el conocimiento exacto del educador (materia) y el dominio de la técnica pedagógica (instrumento); y que en el caso del Perú es el «aborigenismo» (la presencia del indígena) el que «le da matiz específico al ideal educativo", el que le da una personalidad nacional. Se pronuncia por la necesidad de hacer un currículo escolar netamente peruanista.

Sobre los sujetos de la educación, en la década de 1930 reclama que se debe obtener en cada país y región de América «el índice del tipo de niño normal» en la escala respecto a su desarrollo biopsíquico, mereciendo especial atención científica el niño mestizo y el niño aborigen. Galván señala los factores que contribuyen al bajo rendimiento en la educación pública peruana: la mala ubicación de los locales escolares, muchos alumnos por aula, la mayoría de maestros tienen una deficiente preparación, inadecuados ideales de enseñanza con prácticas ajenas a las necesidades locales y criterios homogéneos que norman la labor del maestro (que no ven las diferencias individuales que hay) (Galván, 1925).

Como director de Educación Indígena del Ministerio de Instrucción Pública, Galván insistió en que el folklore, como medio educativo, es una base imprescindible de todo trabajo psicopedagógico (1932a).

\section{Pensamiento sobre la educación indígena}

«Para justificar la dominación es preciso exaltar las virtudes y las cualidades del que domina, así como los defectos y la inferioridad del sojuzgado» (Galván, 1932, p. 9).

Igualmente, aquí trabajamos sobre la base de seis categorías o dimensiones que construimos: valoración del indígena; solución al "problema indígena»; apreciaciones sobre la educación indígena; la educación como «factor de progreso»; la educación "para indios» y la educación bilingüe; el idioma quechua y la castellanización del indígena; y la formación de docentes y el papel de los maestros rurales.

Luis E. Galván es el maestro ayacuchano que para su época tuvo la mejor información sobre la educación indígena a nivel nacional. Debido a los cargos que ocupó en el Ministerio de Instrucción Pública, tuvo contacto con diversas 
personalidades nacionales y del extranjero, con instituciones y comunidades indígenas y con la misma educación indígena.

En la década de 1930, Galván menciona que los indios «constituyen las columnas más firmes y exclusivas de la economía nacional»; que como obreros en las minas triunfan, lo que demuestra una vez más que no hay inferioridad racial, sino carencia de oportunidad. Para justificar su dominación, según Galván, fue necesario que sean vistos como degenerados, alcohólicos, incapaces de redención y que tienen todas las taras de la ociosidad, de la hipocresía, de la mentira y de la desconfianza (1932a).

Señala en la misma década que los niños indígenas tienen «una capacidad manual superior para el modelado, para el dibujo y el colorido impresionista etc., que el (niño) blanco. Posee también cierta insensibilidad más bien por falta de expresión emotiva. Demuestra menor capacidad de vivacidad, pero compensado por un mayor poder del juicio y de la memoria» (Galván 1934a, pp. 3-4).

En la década de 1940, sostiene que lo que pasa es que los indígenas son una clase desvalida, desheredada y abandonada. En la siguiente década, resalta que en el Perú hay una enorme población indígena analfabeta, miserable, sometida a trabajo gratuito y a una organización patriarcal. Sostiene que hay un desmesurado desequilibrio económico entre los hacendados o latifundistas y la extrema pobreza de los campesinos (Galván, 1964), apreciación concordante con otro maestro ayacuchano, Manuel Antonio Hierro Pozo ${ }^{14}$.

Como solución al "problema indígena» y para su transformación, Galván plantea desde la década de 1930 que se requiere de la creación de una «escuela de tipo social» ${ }^{15}$ (lo mismo sostiene en 1941 el maestro ayacuchano Antonio Hierro Pozo, pero lo denomina «escuelas socializadas», como lo señalamos con algún detalle más adelante), que surja del postulado científico psicosocial (1932a), que la escuela más conveniente es la que corresponde a la naturaleza antropológica y al ambiente propio en que vive el indígena. Esta escuela de tipo social, según Galván, debe velar por el desarrollo económico de la población preparando a los escolares en actividades productivas propias del campo (también lo llama escuela de tipo rural), respetando la cultura y el ambiente en que vive el indígena. Para ello, los maestros tienen que compenetrarse

\footnotetext{
14 Coincidentemente Hierro Pozo, en 1941 menciona que los mejores terrenos en Ayacucho se encuentran en poder de los descendientes de españoles; mientras que los campesinos poseen pequeńas tierras que fueron absorbidas "por los propietarios latifundistas colindantes» (Cavero, 2014).

15 Es muy probable que en Hierro Pozo y Galván haya habido en esta parte una influencia de José Antonio Encinas, que con diferencia de matices planteó la «escuela social». Este tema lo desarrolla en un artículo Aurora Marrou (2003).
} 
estrechamente con la comunidad y con cada familia, y deben ser «batallones revolucionarios de renovación social», reemplazando a la iglesia como agente civilizatorio.

Sostiene que para que esto ocurra se debe previamente hacer una investigación integral del indígena (para tener el conocimiento del elemento racial, de sus características psicosociales que pocos antropólogos lo han hecho). Una investigación amplia y científica (sobre "las características sociales, étnicas, etnográficas, culturales y un amplio conocimiento del folklore regional») que hasta ese momento no se había realizado (Galván, 1948). Y él se interesa en advertirlo desde la década de 1930 haciendo esfuerzos en este sentido desde la Dirección de Educación Indígena que ocupó creando una Sección de Investigación Científica sobre el aborigen. Se preocupó de promover la investigación científica integral del indígena, a través de la convocatoria de expertos, para impulsar la Nueva Escuela Indígena y para crear las Escuelas Rurales Indígenas. Esta investigación, ańade, se debe hacer "A fin de no mutilar y perder riquezas espirituales valiosas que tal vez pudieran injertarse en la concepción del mundo occidental significando mayor exuberancia y frondosidad del espíritu humano occidental»(Galván, 1948, p. 2). Como podemos ver, la riqueza espiritual andina, según Galván, bien podría contribuir al enriquecimiento del espíritu humano occidental.

Su posición sobre la solución del "problema indígena», antes focalizada en la educación, sufre un avance significativo en la década de 1940 cuando menciona que el problema indígena desde el punto de vista sociológico y político debe merecer el máximo interés de todo el Perú. Manifiesta que es menester dotarle de las condiciones materiales y espirituales a fin de que disfrute de los "goces de la vida civilizada». Sin embargo, refiere que el problema hay que plantearlo desde el punto de vista puramente socioeconómico, antes que desde el estrictamente racial (Galván, 1948), situación que lo asemeja, con diferencia de matices, a las propuestas de Manuel González Prada y de José Carlos Mariátegui (1968), apartándose aquí de la propuesta oficialista civilista.

En la década de 1960, frente a la extremada inequidad económica existente, concede importancia al factor laboral y legal. Dice que es urgente rectificar las relaciones laborales injustas para impedir una revolución agraria de resultados desconcertantes para toda la sierra peruana (Galván, 1964). Que la legislación debe conservar el régimen del ayllu que tiene como fundamento la solidaridad humana (Galván, 1964b). Sostiene que el indígena debe ser considerado como una persona jurídica integral como el resto de los peruanos, con el goce completo de derechos y obligaciones, de perfecta igualdad ante la ley como prescribe la Carta Fundamental del Estado y sugiere que los personeros de 
las comunidades sean miembros natos de los concejos distritales municipales (Galván, 1964b).

Luis E. Galván (1932a) opina, en la década de 1930, que la educación indígena en el Perú debe condensar los propósitos de la educación contemporánea: crearles el vigor físico, los valores de la higiene y la salud, la fuerza moral, estética y social y aprenda «el manejo de los instrumentos que hace el vehículo de la civilización» (p. 14). La nueva escuela indígena y las actividades escolares deben beneficiar en forma práctica y concreta a la población (Galván, 1932a). Agrega que a través de la educación se busca la mayor perfección del individuo sujeta a sus costumbres, al lugar y a su idiosincracia (Galván, 1932b). Esta escuela más conveniente para los indígenas es la que corresponde a su naturaleza antropológica y al ambiente en que vive (Galván, 1934). Se debe conservar sus raíces históricas, pero adaptándolo al momento presente, a las corrientes ideológicas contemporáneas para que se logre la «perfección racial máxima del peruano» (Galván, 1934a, p. 5).

Se acerca de alguna manera a lo que más tarde sostuvo José María Arguedas (1986), otro destacado literato, maestro y antropólogo indigenista peruano: es menester que la cultura andina no quede petrificada, sino cambie y se adecué a las exigencias de la modernidad. Lo que es cuestionable es que estos cambios permitirían, según el maestro ayacuchano, la "perfección racial del peruano» y que el indígena disfrute de los goces de la vida civilizada. Así, para Galván, el indígena sería una especie semicivilizada o falto de civilización y que lo que se debe hacer es incorporarlo «a la corriente civilizadora contemporánea» (1930, $\mathrm{s} / \mathrm{p}$ ), que la función de educar al indio es civilizadora (Galván, 1932b), que la escuela indígena debe fecundar «en civilización y bienestar el espíritu del ayllu» (Galván, 1934, p. 3), etc. Aquí Galván habría interiorizado la propuesta oficialista del proyecto educativo civilista que fue cuestionada, y se apartó a este respecto de José Antonio Encinas, otro destacado maestro indigenista ${ }^{16}$.

Las escuelas tradicionales, según el maestro ayacuchano, solo enseñan a leer, a escribir y a contar (es una escuela alfabetizante), lo que es negativo. Las escuelas rurales o la nueva escuela indígena tienen que beneficiar en forma práctica y concreta a la población (Galván, 1932); deben extender su acción constructiva sobre la comarca y sacudir la vida de todo el ayllu. Se debe promover la escuela de acción y la escuela productiva, con la manualidad como eje del aprendizaje. Valora, en este sentido, las experiencias educativas de México (en particular las «escuelas rurales» de orientación social) y Rusia (Galván, 1934a). En esta parte existen coincidencias con el maestro ayacuchano Antonio Hierro Pozo que, en

16 Para Encinas es imposible querer civilizar al indio «mediante la escuela» (Marrou, 2003, p. 14). 
1941, plantea la necesidad de «escuelas socializadas» ${ }^{17}$, aunque disiente en otros tópicos.

Galván ve con sumo interés el proceso ideológico, los cambios culturales y educativos en México, así como la educación rusa. Bajo su liderazgo se publica artículos a este respecto (Quipu No 2, 1931). Consideró necesaria la instalación de las Escuelas Rurales de orientación social al estilo de estos países (1934b, p. 2). Estaba al tanto y era invitado a los Congresos Indigenistas Interamericanos de Perú y Bolivia (cuya sede oficial fue México) y leía la revista América Indígena del Instituto Indigenista Interamericano (México).

Desde los años 1920, en México hay un interesante debate sobre la educación en general y sobre la educación indígena en particular; uno de los que encabeza es el filósofo y político José Vasconcelos (1882-1959) ${ }^{18}$. Al respecto encontramos coincidencias y discordancias entre Galván y el exministro de Educación Pública. El mexicano propone la total «integración» $\mathrm{y}$ «asimilación» del indígena a la nacionalidad, a la civilización europea, por tanto, la necesidad de una escuela única (escuela común para todos) y su total castellanización. En similar posición se encontraba en México el historiador Emilio Rabasa y José María Puig, este último sucesor de Vasconcelos en la Secretaría de Educación Pública. Claro que también había otros en México como Lucio Tapia que eran partidarios de la llamada «reservación»; es decir, de «escuelas indígenas» como internados para indios (Fell, 1989). Galván ve la necesidad de impulsar las «escuelas indígenas» (que también lo planteaba en Ayacucho el maestro Manuel Antonio Hierro Pozo), pero sin considerar como Hierro Pozo y Lucio Tapia a estas escuelas como guetos aislados de las otras culturas. También se aleja radicalmente de

17 Las «escuelas socializadas», para Hierro Pozo deben extender su radio de acción entre los adultos, siquiera hasta las casas vecinas «mejorando la forma de vivir de sus habitantes, que virtualmente resultaría vinculados a los establecimientos de enseñanza» (Cavero, 2014, p. 276). Agrega, las escuelas indígenas deben ser "productoras de pequeńas industrias agropecuarias, teniendo en cuenta el idioma, las producciones geográficas y las necesidades de cada localidad, es decir, según el medio, con solo el fin desinteresado de cooperar a la resolución de los problemas indígenas» (Cavero, 2014, p. 273).

18 El Perú, no fue ajeno al pensamiento y a las obras de José Vasconcelos. En 1924, el poeta provinciano Adalberto Varallanos publica una antología de José Vasconcelos con una portada diseñada por el artista plástico César Moro. Varallanos fue recluido en la cárcel por el dictador Leguía porque, según sus captores, la obra contenía un mensaje antinorteamericano. En la revista Amauta de 1925 a 1930 hay artículos sobre la revolución mexicana y, es muy probable, escritos sobre este destacado y polémico pensador autor de Ulises criollo. Más tarde, Mariátegui escribe Temas de nuestra América (1959) dedicándole muchas páginas a la revolución mexicana y también se refiere a Vasconcelos. Galván, a diferencia de Vasconcelos tenía menos poder dentro del campo cultural y dentro del campo educativo nacional; el autor de La raza cósmica, desde el cargo que ocupó, emprendió una revolución cultural importante en su país, mientras que el maestro ayacuchano no tuvo esta dimensión. Coinciden en que a ambos les asistía una gran energía y vocación y el sueño de realizar grandes cambios educativos y culturales en sus países. 
Vasconcelos por su predilección a conservar las lenguas indígenas e impulsar la educación bilingüe, poniéndose así más cerca al mexicano Manuel Gamio. En otros temas hubo acercamientos entre el revolucionario Vasconcelos (que luchó contra la tiranía y los privilegios) y el indigenista Galván, como el de la civilización del indígena y que este debía ser integrado al desarrollo social.

Más adelante, en la década de 1950, respecto a Ayacucho Galván dirá que necesita escuelas adecuadas a las características ruralistas y a la economía subdesarrollada de la región (1958).

Sobre las lenguas originarias, el 5 de diciembre de 1931, se emite la resolución suprema 1593, expresando la complacencia del gobierno por la cooperación desinteresada de varios intelectuales al estudio de la escritura del alfabeto de las lenguas aborígenes; igualmente, se nomina una comisión para redactar, de acuerdo al alfabeto presentado, un diccionario oficial de las lenguas aborígenes. Firman la resolución David Samanés Ocampo (presidente) y Luis E. Galván (director de Educación Indígena) (Cavero, 2014, p. 46) ${ }^{19}$.

Mucho tiempo después, en la década de 1950, Galván escribe dos trabajos sobre las lenguas aborígenes, uno de ellos sobre la filología del runa $\operatorname{simi}^{20}$. En 1958, abogó para que en la Universidad Nacional de San Cristóbal de Huamanga se forme el Instituto de Lingüística y se estudie las lenguas vernáculas como el quechua y el aimara y los idiomas extranjeros vivos. Valora al quechua y señala que después de la independencia del colonialismo español solo se oficializó el idioma castellano.

Aquí encontramos una diferencia con otros destacados maestros indigenistas miembros del Centro Cultural Ayacucho (Manuel Antonio Hierro Pozo, Manuel E. Bustamante Jerí, Moisés Cavero Cazo, Lucio Alvizuri Bendezú y Luis Milón Bendezú Fajardo) que reconocen la importancia de la castellanización para incorporar al indígena a la civilización (y a la nacionalidad). Bustamante se extraña que hasta la fecha no se haya logrado este propósito. Hierro Pozo reclama que los indígenas deben ser desanalfabetizados y castellanizados para incorporarlos a la nacionalidad, pero que esta castellanización no debe significar dejar de hablar el quechua, postura que se asemeja a la del profesor Moisés Cavero Cazo (Cavero, 2014). No hemos encontrado ideas semejantes en Galván. Más bien sugiere que en las universidades, escuelas

19 En enero de 1932, en el número 2 de la publicación realizada por la Dirección General de Enseñanza- Dirección de Educación Indígena, se edita el documento «La escritura del alfabeto de las lenguas aborígenes del Perú» (Lima: Imprenta Americana). Según otra fuente, se trata de "Las escrituras del alfabeto quechua».

20 Este último lo somete a consideración del agregado cultural de la embajada de Estados Unidos y de la Universidad de Cornell. 
superiores e institutos de cultura superior sea obligatorio el aprendizaje del quechua (1959b). De esta forma nuevamente se aleja del proyecto educativo nacional civilista y se acerca al proyecto educativo nacional indigenista.

Al parecer fue muy tardía la preocupación de Galván por la educación bilingüe. Recién manifiesta en la década de 1960 que desgraciadamente la alfabetización en las zonas rurales se realizaba solo en el idioma castellano, a excepción de Cusco y Puno donde la alfabetización bilingüe tuvo éxito (1964c). Dice que hay sugerencias para que haya textos bilingües, cartillas y diccionarios bilingües y que no desaparezcan las lenguas aborígenes, pero que hasta la fecha solo quedaban en proyectos y buenos propósitos (1964c). En esta parte hay cierta coincidencia con José María Arguedas, que se preocupó por «legitimar el estatus del quechua» y defendió tajantemente este idioma como punto de partida de la alfabetización, sin menoscabo a que los indígenas aprendan y hagan suyo el castellano, pero no en forma impositiva, sino por el «método cultural» (Kapsoli, 2003).

Sobre la formación de docentes y el papel de los maestros rurales su preocupación viene desde la década de 1930. Se pronuncia por la necesidad de crear escuelas normales rurales indígenas para la formación de maestros, en las que se priorice a los elementos jóvenes propios de las comunidades y se compenetren fácilmente con la comunidad, para enseñarles a criar a los nińos, imponer la higiene, aumentar la producción agrícola y desterrar la brujería, la hechicería, la superstición. Para lo cual, según el maestro ayacuchano, es crucial la vocación del maestro. Enseguida menciona que los educadores peruanos «son capaces de reconstruir nuestra vigorosa nacionalidad», «reafirmar la realidad indo-americana [...] dignificando a una raza oprimida por el desprecio y la explotación» (1932a, p. 2). Si bien Galván plantea la necesidad de reconstruir la nacionalidad, esta no es a partir de la castellanización del indígena como plantearon otros maestros indigenistas ayacuchanos de la época, sino a través de la reafirmación de la realidad indoamericana y de la dignificación de la raza oprimida. Aquí, nuevamente, la presencia de la raza indígena como sinónimo de cultura andina, es determinante para construir la nacionalidad ${ }^{21}$, incorporando a las masas mestizas y aborígenes en esta. Así, Galván se va acercando nuevamente al proyecto educativo nacional indigenista.

\footnotetext{
21 La preocupación por el problema nacional fue el centro del debate en la vida intelectual peruana durante la década de 1920 en adelante y adquiere una dimensión generacional. Recién en la década 1920 surgen ciertos movimientos y partidos que empiezan a abogar por una unidad nacional y cuestionan el poder de la oligarquía y del imperialismo. Es que el Perú en aquella época no era una nación en el término exacto de la palabra. En este contexto, ambos proyectos educativos nacionales: el civilista y el indigenista buscan, a su manera, la incorporación del indígena a la nación peruana.
} 
En esta década menciona que los maestros deben tener un verdadero carińo por la raza y por la misión a emprender, adaptados a las tradiciones y costumbres, las que después deben ser modificadas (por ejemplo, según el maestro ayacuchano, se debe desterrar la brujería, la hechicería y la superstición), situación muy discutible, por cierto. Enfatiza que los maestros deben ser soldados en la gran batalla por la salvación de la raza, y por ende de la nacionalidad (Galván, 1932a).

En la década de 1950 es del parecer que los maestros que debían formarse en el Instituto de Educación, pronto a crearse en la reabierta Universidad de Huamanga, tengan una orientación ruralista. Aboga por un:

magisterio rural-urbano eficiente, con amplio conocimiento del medio, con dominio de los idiomas nativo y dotado de capacidad para promover el progreso social de los pueblos en cuya seño (sic) prestará sus servicios. Se pondrá énfasis en su orientación ruralista, a fin de que pueda emprender la lucha contra el analfabetismo y en pro de la incorporación de las masas mestizas y aborígenes a la nacionalidad (Galván,1958, p. 66).

Finalmente, para Galván, las escuelas rurales deben ser égidas sociales, extender sus acciones constructivas sobre las comarcas y sacudir la vida de todo el ayllu. Deben agitar, renovar y remecer todo el marasmo de prejuicios tradicionales que aprisionan la mentalidad del indio peruano. En esta cruzada, la labor del maestro era crucial.

\section{Conclusiones}

1. Al interior del prestigioso Centro Cultural Ayacucho, Luis E. Galván estuvo entre quienes tuvieron un mayor capital simbólico, más «poder implícito en el ser social del profesor» como señala Perafán, y mayor poder político: fue dos veces senador de la República en representación de Ayacucho. La producción de bienes simbólicos tiene que ver más con sus propuestas sobre la educación indígena, publicadas en libros, revistas y expuestas en conferencias desarrolladas en las décadas de 1920 a 1960 y en su accionar cultural en este periodo. Sin embargo, en el plano nacional fue opacado por el centralismo académico limeño y los conflictos al interior del campo intelectual en el que predominaba posiciones conservadoras, oligárquicas y extranjerizantes.

2. Su labor intelectual fue prolífica, a pesar de su escasa vinculación con la docencia universitaria, ya que como dice Carlos Altamirano (2013, p. 132) «La universidad está en el corazón del contexto institucional que produce 
las élites intelectuales en la sociedad contemporánea». Sin embargo, Galván era un intelectual que estaba imbuido de una «cultura del discurso crítico», en los términos de Alvin Goulder (citado por Altamirano), en la que vale la fuerza del mejor discurso, no la referencia a la posición social o a la autoridad del hablante.

3. De las seis corrientes indigenistas desarrolladas en Ayacucho, Galván (junto al maestro Manuel Antonio Hierro Pozo y otros) pertenece al indigenismo académico temprano de maestros de educación básica, con ideas más elaboradas y con visiones más integradoras. Fue un indigenismo «moderno" para la época, cercano a Luis E. Valcárcel, uno de los indigenistas más destacados del Perú (quien exalta la grandeza del Imperio incaico y es antihispanista), aunque con ingredientes propios como la fuerte valoración del quechua, asemejándose al indigenismo del maestro José María Arguedas y del maestro ayacuchano Moisés Cavero Cazo. El de Galván es un indigenismo que se enfrenta a Espańa, a Pizarro y a la colonia, con lo que se distancia de Cavero; también se diferencia de este y del mexicano José Vasconcelos porque no planteó la asimilación del indio a la civilización a través de su castellanización.

4. Galván asumió plenamente el influjo de la Escuela Nueva e impulsó las escuelas de métodos activos. Frente a los indígenas, al inicio interiorizó de alguna manera la propuesta oficialista del proyecto educativo homogeneizador civilista (asimilacionista, de incorporarlo a la "civilización» a través de su castellanización). Después se fue distanciando de este proyecto y se acercó al proyecto educativo nacional indigenista que reconoce virtudes en la cultura indígena que debían ser preservadas, que plantea la alfabetización del indígena en su propio idioma autóctono, entre otros; también porque relacionó el "problema indígena» al "problema nacional» y el «problema indígena» fue visto como económico-social y no racial, y se aproximó así a las propuestas, con diferencia de matices, de González Prada, Mariátegui, Encinas y Arguedas. Es en el Perú uno de los prolegómenos tempranos más importantes del paso de la «educación para indios» a la educación bilingüe y de esta a la educación intercultural.

5. Galván, así como otros indigenistas peruanos, valoraron la revolución cultural y las experiencias educativas de México desarrolladas particularmente desde los años en que José Vasconcelos es titular del Ministerio de Educación Pública (1921) (antes Secretaría de Educación Pública). Entre Galván y el controvertido Vasconcelos hubo muchas coincidencias, sin embargo, 
en el debate de la época sobre la educación indígena —en sus propuestas medulares-, el maestro ayacuchano se fue alejando respecto a las del autor de La raza cósmica. En este campo, las propuestas del pensador mexicano se asemejarían más a las propuestas del proyecto educativo nacional civilista que se desarrollaba en el Perú.

6. En Ayacucho, las demandas sociales más generales y recurrentes en la primera mitad del siglo XX eran: la necesidad de mejorar la educación sobre todo en el medio rural a través de la «escuela de tipo social» — para Hierro Pozo "escuelas socializadas», aunque contrario a Galván propuso que estas «escuelas indígenas» serían internados para indios; y para Encinas (2007) «escuela social»—, construir una identidad cultural ayacuchana, pugnar por el desarrollo de Ayacucho y buscar la reapertura de su antigua Universidad. Sobre estas demandas Galván y otros maestros del Centro Cultural Ayacucho se unían y se diferenciaban al interior del campo intelectual; las formas de abordarlo y los mecanismos de lograrlos variaba. A Luis E. Galván se le reconoce como uno de los gestores más importantes de la reapertura de la Universidad de Huamanga. El renombre de Galván fue evidente, la sociedad ayacuchana reconoció sus valores y la verdad de sus obras.

7. No obstante los conflictos al interior del campo intelectual desfavorable para Galván en el ámbito nacional, en la competencia por su consagración cultural, pesó mucho su conocimiento global (macro) de la educación nacional; sus publicaciones editadas en Ayacucho y Lima, sus contactos con intelectuales de Lima y del extranjero; el ser miembro del Centro Cultural Ayacucho y haber sido funcionario del Ministerio de Instrucción Pública. Al lado de destacados intelectuales ayacuchanos y de otros lugares, fue miembro de la Comisión Central y otras comisiones menores en la reapertura de la Universidad de Huamanga (1954-1957).

8. Galván participó en los temas y problemas de orden del día común a los maestros intelectuales ayacuchanos, particularmente sobre la educación indígena. Se comunica no solo con los intelectuales ayacuchanos sino con otros a nivel nacional a quienes también dirige sus obras. Siguiendo a Bourdieu diremos que Galván debe a la escuela los lugares comunes (campos de encuentro y campos de entendimiento, problemas comunes y formas comunes de abordar estos problemas comunes) y disputas en torno a los mismos objetivos (por ejemplo, es muy conocida su actitud contraria cuando fue cerrada por intereses políticos la primera escuela rural indígena de Soccoscocha-Huanta). Había estudiado en un colegio de prestigio en 
Ayacucho y en la Escuela Normal de Varones de Lima. Al retornar a su tierra trabajó en colegios emblemáticos como San Ramón y el Mariscal Cáceres y luego en el Ministerio del ramo; fuerzas que formaron su habitus.

9. Siendo de la generación temprana de intelectuales ayacuchanos vinculado al campo educativo del siglo XX, participó del tópico y la retórica (y metáforas) propios de la época «como un conjunto común de temas y formas, que definen la tradición cultural de una sociedad y de una época» como señalara Bourdieu.

10. La relación de Galván con su clase social de origen o de pertenencia (mestizo de la clase pudiente, vinculado a la hacienda tradicional) fue refractada por la estructura del campo intelectual: fue mediatizada por la posición que ocupó en el campo intelectual, en función de la cual se acercó más a posiciones indigenistas y fue crítico frente a los poderes nacionales dominados por grupos económicos y sociales y de empresas mineras norteamericanas.

\section{REFERENCIAS BIBLIOGRÁFICAS}

Altamirano, C. (2013). Intelectuales. Notas de investigación sobre una tribu inquieta. Buenos Aires: Siglo veintiuno.

Amauta (1929). Revista Mensual de Doctrina, Literatura, Arte, Polémica. Director José Carlos Mariátegui. Lima, Año III, N. 24, Sociedad Editora «Amauta».

Arguedas, J.M. (1986). Nosotros los maestros. Presentación y selección de Wilfredo Kapsoli. Lima: Editorial Horizonte.

Bourdieu, P. (2002). Campo de poder; campo intelectual. Itinerario de un concepto. Buenos Aires: Editorial Montressor.

Bustamante, M.E. (1943). Apuntes para el folklore peruano. Ayacucho: Imprenta La Miniatura.

Cavero, R. (2014). La educación de los excluidos. Ayacucho 1900-1961. Lima: Edit. San Marcos.

Cavero, R. (2015). El pensamiento y los aportes del maestro ayacuchano Manuel Antonio Hierro Pozo. Tercer Informe Parcial de Investigación (inédito). Ayacucho: Instituto de Investigación de la Facultad de Ciencias de la Educación de la Universidad Nacional de San Cristóbal de Huamanga.

Cavero, R. y Cavero, R. (2007). Retablo de memorias. Indigenas e indigenismo en Ayacucho. Lima. 
Chileno, J. (s/f). La Nueva Escuela en la Facultad de Educación de la Universidad Nacional Mayor de San Marcos. Lima: s/e.

De Arruda, M.L. (1996). História da educação. 2da. edición. São Paulo: Editora Moderna.

Encinas, J.A. (2007). Un ensayo de Escuela Nueva. Con prólogo de José Portugal. Puno: UNAP.

Fell, C. (1989). José Vasconcelos. Los años del Águila (1920-1925). Educación, cultura e iberoamericanismo en el México postrevolucionario. México: Universidad Nacional Autónoma de México.

Galván, L.E. (1925). Hacia la escuela renovada. Lima: Editorial Garcilaso.

Galván, L.E. (1930). Moción de Orden ante el VI Congreso Panamericano del Niño. Lima.

Galván, L.E. (1932a). «Aspectos del problema educativo de las masas aborígenes Del Perú». Borrador escrito a máquina.

Galván, L.E. (1932 b). «Conferencia para la Asociación de Maestros Primarios de Lima». Borrador escrito a máquina.

Galván, L.E. (1934a). «Encuesta del Primer Congreso Nacional Indígena del Perú». Lima. Borrador escrito a máquina.

Galván, L.E. (1934b). «Encuesta a la intelectualidad Indigenista del Perú». Lima. Borrador escrito a máquina.

Galván, L.E. (1948). Mi saludo a los estudiantes y profesores del Colegio Nacional "Mariscal Cáceres» de Ayacucho, en su fecha centenaria. Lima: Ediciones Folklore.

Galván, L.E. (1958). La UNSCH 1677-1958. Reflexiones sobre una pedagogía universitaria aplicable al Perú. Lima: Talleres Gráficos de T. Scheuch S.A.

Galván, L.E. (1959a). Ayacucho semblanza de la ciudad. Lima: Imprenta D. Miranda.

Galván, L.E. (1959b). «Filología de la Lengua Keshwa o Runa Simi Idioma General Hablado desde el Imperio de los Incas». Trabajo mecanografiado y con correcciones.

Galván, L.E. (1964). Bases jurídicas y económicas para la integración del aborigen peruano a las fuentes de producción y de consumo para la solución de problemas de las comunidades campesinas. Ponencia. Lima, 02 de agosto.

Galván, L.E. (1964b). «La población indígena y los planes de desarrollo económico social».

Galván, L.E. (1964c). El papel de las lenguas aborígenes en el proceso de Incorporación del indígena a la vida nacional. Ponencia. Lima, 30 de agosto.

Galván, L.E. (s/f). El problema educacional del aborigen peruano. Mecanografiado. 
Kapsoli, W. (2003). El maestro José María Arguedas. En Ministerio de Educación, Grandes maestros peruanos (pp. 273-301). Lima.

Lazarín, F. (s/f). José Vasconcelos. Apóstol de la educación. Recuperado de http:// www.uam.mx/difusion/casadeltiempo/25 iv nov 2009/casa del tiempo eIV num25 04 10.pdf

López, S. (2009). Cavernícolas y mundo andino. Diario La República. Lima.

Mariátegui, J.C. (1968). 7 Ensayos de Interpretación de la Realidad Peruana. Décimo tercera edición. Lima: Biblioteca Amauta.

Marrou, A. (2003). José Antonio Encinas Franco. En Ministerio de Educación, Grandes maestros peruanos (pp. 11-27). Lima.

Ministerio de Instrucción Pública. Dirección General de Enseñanza (1932). Las escrituras del alfabeto quechua 2. Lima: Dirección de Educación Indígena.

Perafán, G., Adúriz-Bravo, A. (comps.) (2005). Pensamiento y conocimiento de los profesores. Debate y perspectivas internacionales. Bogotá: Universidad Pedagógica Nacional.

Quipu (1931). Revista de la Dirección de Educación Indígena del Ministerio de Instrucción Pública, $\mathrm{N}^{\circ} .1$ y 2 . Lima. 